CLINICAL STUDY

\title{
High-dose GH treatment limited to the prepubertal period in young children with idiopathic short stature does not increase adult height
}

\author{
S A van Gool, G A Kamp ${ }^{1}$, R J Odink ${ }^{2}$, S M P F de Muinck Keizer-Schrama ${ }^{3}$, H A Delemarre-van de Waal ${ }^{4}$, \\ W Oostdijk and J M Wit \\ Department of Pediatrics, Leiden University Medical Center, Postal Zone J6-S, Albinusdreef 2, 2333 ZA Leiden, The Netherlands, ${ }^{1}$ Department of Pediatrics, \\ Tergooi Hospitals, Blaricum, The Netherlands, ${ }^{2}$ Department of Pediatrics, Catharina Hospital, Eindhoven, The Netherlands, ${ }^{3}$ Subdivision Endocrinology, \\ Erasmus Medical Center/Sophia Children's Hospital, Rotterdam, The Netherlands and ${ }^{4}$ Department of Pediatrics, VU University Medical Center, \\ Amsterdam, The Netherlands \\ (Correspondence should be addressed to S A van Gool; Email: s.van_gool@lumc.nl)
}

(H A Delemarre-van de Waal is now at Department of Pediatrics, Leiden University Medical Center, Leiden, The Netherlands)

\begin{abstract}
Objective: To assess the long-term effect of prepubertal high-dose GH treatment on growth in children with idiopathic short stature (ISS).

Design and methods: Forty children with no signs of puberty, age at start 4-8 years (girls) or 4-10 years (boys), height SDS $<-2.0$ SDS, and birth length $>-2.0$ SDS, were randomly allocated to receive GH at a dose of $2 \mathrm{mg} / \mathrm{m}^{2}$ per day (equivalent to $75 \mu \mathrm{g} / \mathrm{kg}$ per day at start and $64 \mu \mathrm{g} / \mathrm{kg}$ per day at stop) until the onset of puberty for at least 2 years (preceded by two 3-month periods of treatment with low or intermediate doses of GH separated by two washout periods of 3 months) or no treatment. In 28 cases, adult height (AH) was assessed at a mean (s.D.) age of 20.4 (2.3) years.

Results: GH-treated children (mean treatment period on high-dose GH 2.3 years (range 1.2-5.0 years)) showed an increased mean height SDS at discontinuation of the treatment compared with the controls $(-1.3(0.8)$ SDS versus -2.6 (0.8) SDS respectively). However, bone maturation was significantly accelerated in the GH-treated group compared with the controls (1.6 (0.4) versus $1.0(0.2)$ years per year, respectively), and pubertal onset tended to advance. After an untreated interval of 3-12 years, $\mathrm{AH}$ was $-2.1(0.7)$ and $-1.9(0.6)$ in the $\mathrm{GH}$-treated and control groups respectively. Age was a positive predictor of adult height gain.

Conclusion: High-dose GH treatment restricted to the prepubertal period in young ISS children augments height gain during treatment, but accelerates bone maturation, resulting in a similar adult height compared with the untreated controls.
\end{abstract}

European Journal of Endocrinology 162 653-660

\section{Introduction}

GH treatment in children with idiopathic short stature (ISS) has been the subject of many clinical trials. There are essentially four outcome parameters of $\mathrm{GH}$ treatment that can be considered: short-term growth response (first year's height velocity), bone age (BA) advance, onset and progress of puberty, and increase in adult height (AH). As recently reviewed $(1,2)$, almost all children with ISS respond to GH treatment with an increase in height velocity, even at a relatively low dose. The dose-response curve for the first year's height velocity appears to reach a plateau after a dose of $50 \mu \mathrm{g} / \mathrm{kg}$ per day. No acceleration of BA advance and pubertal onset and progress has been observed in the dose range of $30-53 \mu \mathrm{g} / \mathrm{kg}$ per day, and the most effective dose regimen (50 $\mu \mathrm{g} / \mathrm{kg}$ per day) leads to $\sim 7 \mathrm{~cm}$ AH gain $(1,2)$.
At the time this study was designed, there were three important issues with respect to $\mathrm{GH}$ treatment of children with ISS that awaited resolving. First, it was unknown what the effect would be of a further increase of the GH dosage on growth velocity, bone maturation, puberty, and AH. Secondly, the relative contribution of GH treatment before and during puberty was unclear. Thirdly, there was a need to gain more insight into the factors affecting the growth response, as only a modest part of the inter-individual variation can be explained (3).

In order to address these issues, we started a controlled clinical trial in children with ISS in 1993. We hypothesized that a high GH dose before puberty might be able to bring height within the population's range, as shown for a dose of $0.1 \mathrm{mg} / \mathrm{kg}$ per day (4), without undue bone maturation and advance in 
puberty, and without adverse effects. We limited the period of GH therapy to the years before pubertal onset, primarily to improve the cost-benefit ratio, but also based on studies showing that HSDS at the onset of puberty is a strong predictor of $\mathrm{AH}$ in GH-deficient children $(5,6)$, and that pubertal height gain on $\mathrm{GH}$ treatment was not different between GH-treated children and untreated controls (7). In order to improve the predictive power of clinical and biochemical variables, we included an elaborate assessment of GH sensitivity.

In three previous papers on this study, we reported that high-dose GH limited to the prepubertal period increased growth, but also advanced BA maturation and pubertal development, so that the predicted $\mathrm{AH}$ (PAH) did not change (8), and that biochemical (9) and in vitro (10) indices of GH sensitivity had little predictive power for the short-term growth response. In the present paper, we report the results on $\mathrm{AH}$.

\section{Subjects and methods}

\section{Patients}

This report includes AH data on 28 of 40 children with ISS who originally enrolled in a multicenter study in The Netherlands from December 1993 to December 1996. Inclusion criteria were as follows: no signs of puberty (G1 in boys and B1 in girls); height at baseline $\left(H_{\text {start }}\right.$ SDS $)<-2.0$ SDS for Dutch references available at that time (11), age at baseline 4-8 years for girls and 4-10 years for boys; birth length $>-2.0$ SDS (12); maximum serum GH level more than $10 \mu \mathrm{g} / \mathrm{l}(1 \mathrm{mg}$ $=2 \mathrm{IU}$, using World Health Organization International RP $66 / 217$ as standard) after provocation (exercise, arginine, clonidine, L-dopa, or glucagon); and a normal sitting height $(\mathrm{SH}) /$ subischial leg length (LL) ratio (between P3 and P97) (13). Screening blood tests and urinalysis were normal. No organic causes of growth failure, primary bone disease, chronic illness, or dysmorphic syndrome were present. Further details of the subjects and data obtained after discontinuation of treatment have been reported previously $(8,9)$.

Three children of Turkish origin were included in the trial: one girl and one boy in the GH-treated group, and one boy in the control group. $H_{\text {start }}$ SDS was calculated using Dutch references $(-2.50,-2.73$, and -3.23 respectively), and their height was also $<-2$ SDS for references for Turkish children that became available in 1997 (14). For further analyses, SDS values of these and all other children were calculated using references for Dutch children.

The protocol was approved by the medical ethical review boards at the three participating centers (Amsterdam, Rotterdam, and Eindhoven). Before conducting any study-related procedure, written informed consent was obtained from parents and, when appropriate, also from the participants. For $\mathrm{AH}$ analysis, written informed consent was obtained from the participants. This clinical trial was registered in the metaRegister of Controlled Trials (ISRCTN52337368) of the Current Controlled Trials Ltd (London, UK).

\section{Study design}

Forty patients were randomly allocated to receive GH treatment or no treatment (Fig. 1). Details have been reported previously (8). In short, in the GH treatment group, GH responsiveness was assessed during the first year of the study by administering $\mathrm{GH}$ in an on-off scheme at a dose of 0.5 or $1.0 \mathrm{mg} / \mathrm{m}^{2}$ per day (equivalent to 19 or $38 \mu \mathrm{g} / \mathrm{kg}$ per day respectively) during two periods of 3 months, separated by two washout periods of 3 months without $\mathrm{GH}$ treatment (Fig. 2). In the second year, long-term GH treatment with $2.0 \mathrm{mg} / \mathrm{m}^{2}$ per day (75 $\mu \mathrm{g} / \mathrm{kg}$ per day) was started and was intended to be given for at least 2 years. Treatment was discontinued at the first full year visit after the onset of puberty (G2 for boys and B2 for girls), which resulted in a treatment period of 2-5 years on high-dose GH (mean 2.3 years). At discontinuation of $\mathrm{GH}$ treatment, the dose was equivalent to $64 \mu \mathrm{g} / \mathrm{kg}$ per day. The GH dose per $\mathrm{kg}$ body weight was lower at discontinuation of treatment than at start of the highdose treatment phase due to the fact that body weight shows a larger increase with age than body surface. GH (Genotropin, Pfizer Inc., New York, NY, USA) was administered subcutaneously, 7 days per week between 1800 and $2000 \mathrm{~h}$. The measurements at discontinuation of treatment in the GH-treated group were compared with measurements after attaining Tanner stage 2 (B2 for girls and G2 for boys) in the control group.

Directly after randomization, four patients (two from each group) refused to start the treatment they were randomly allocated to receive and dropped out (Fig. 1). In addition, one boy from the GH treatment group was found to have neurofibromatosis and was excluded from the study.

At AH analysis, six patients from the control group could not be motivated to participate. One patient from the GH-treated group could not be traced and was lost to

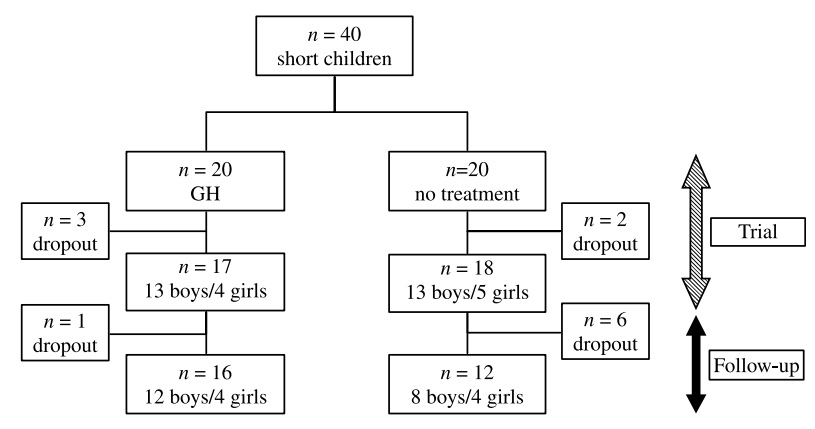

Figure 1 Trial design. 


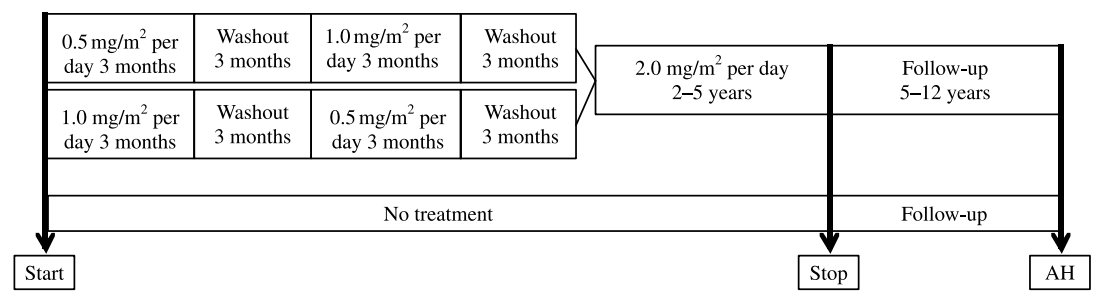

Figure 2 Time scheme for $\mathrm{GH}$-treated and control groups. GH doses: $0.5 \mathrm{mg} / \mathrm{m}^{2}$ per day $=19 \mu \mathrm{g} / \mathrm{kg}$ per day; $1.0 \mathrm{mg} / \mathrm{m}^{2}$ per day $=38 \mu \mathrm{g} / \mathrm{kg}$ per day; and $2.0 \mathrm{mg} / \mathrm{m}^{2}$ per day $=75 \mu \mathrm{g} / \mathrm{kg}$ per day. follow-up. One boy stopped using high-dose GH after 1.2 years and could not be motivated to continue according to the protocol. However, his growth data are included in this report. Pubertal onset and development were not registered for one girl from the control group, and her last known auxological information at the age of 9.7 years was used for the analysis at study end.

At follow-up, we took a short medical history, performed a physical examination; assessed BA (15); and measured height, weight, and SH. LL was obtained by subtracting $\mathrm{SH}$ from height. Blood was collected for DNA extraction and single-nucleotide polymorphism genotyping (SNP array) as described before (16) using the Affymetrix Genechip Human Mapping 250 K array set. We also assessed the psychosocial status, which will be reported separately.

\section{Outcome parameters}

Four outcome parameters were used to evaluate the response to treatment: i) AH SDS; ii) AH minus height at start SDS ( $\mathrm{AH}-H_{\text {start }}$ SDS); iii) AH minus height for BA at start $\left(\mathrm{AH}-\mathrm{H}\right.$ for $\left.\mathrm{BA}_{\text {start }} \mathrm{SDS}\right)$; and iv) $\mathrm{AH}$ minus conditional target height (cTH) SDS (AH-cTH SDS). Because of the young BA of most patients at start of the intervention, the PAH according to Bayley \& Pinneau (17) could not be calculated at start.

To assess the degree of change of growth potential after discontinuation of treatment, we analyzed AH SDS minus $\mathrm{PAH}$ at discontinuation of therapy $\left(\mathrm{AH}-\mathrm{PAH}_{\text {stop }}\right.$ SDS). For both groups, pubertal development at Tanner stage 2 was expressed as SDS for age and gender according to a recent technique (18).

Height and body mass index (BMI) SDS were based on recent Dutch references (19). For calculation of AH SDS, the age of each patient was set at 21 years, enabling comparison of $\mathrm{AH}$ with the height distribution in the normal adult population. For four patients, a BA radiograph at discontinuation of treatment was not available, but BA was extrapolated from a BA determination closest to this time point (at visit $\mathrm{x}$ ) using the formula: $\mathrm{BA}_{\text {stop }}=\left(\mathrm{BA}_{\text {visit } \mathrm{x}} / \mathrm{CA}_{\text {visit } \mathrm{x}}\right) \times$ age $_{\text {stop }}$.

A total of 24 of 28 patients consented to undergo an X-ray of the left hand for automatic determination of the pediatric bone index (PBI), an index for the amount of cortical bone specifically developed for the pediatric population (20). PBI was expressed as SDS based on a Dutch reference cohort. For patients older than 19 years, SDS values were calculated using references for 19-year-old adolescents.

Parental height SDS was calculated and corrected for the secular trend (in The Netherlands estimated at $4.5 \mathrm{~cm} / 30$ years) as follows: height $t_{\text {father }}$ $\mathrm{SDS}=\left(\left(\mathrm{AH}_{\text {father }}+4.5\right)-184\right) / 7.1$ and height $\mathrm{mother}$ $\mathrm{SDS}=\left(\left(\mathrm{AH}_{\text {mother }}+4.5\right)-170.6\right) / 6.5$ (19). cTH, which is the target height corrected for the effect of assortative mating and parent-offspring correlations, was calculated using the formula: cHT SDS $=0.72 \times$ the average of father's and mother's height SDS (21).

The SH, LL, and SH/H ratio were expressed in SDS based on Dutch references (22). For calculation of adult SH SDS, LL SDS, and SH/H SDS, the age of each patient was set at 21 years.

\section{Statistical analysis}

The study was designed to compare the effects of highdose GH treatment with those of no treatment on AH. Statistical analyses were performed using the statistical package SPSS version 14.0 (SPSS, Chicago, IL, USA). Results are expressed as mean (S.D). Comparisons among treatment and control groups were made using Student's unpaired $t$-tests. Possible interactions between the effect of GH treatment on the outcome parameters and the baseline parameters gender, age $\left(\right.$ age $\left._{\text {start }}\right)$, height $\left(H_{\text {start }}\right.$ SDS), and BA delay were analyzed by means of linear regression analysis using ANOVA applied to the whole group of subjects. Possible associations between insulin-like growth factor 1 (IGF1) SDS after 3 months or 1 year of treatment with $2.0 \mathrm{mg} / \mathrm{m}^{2} \mathrm{GH}$ and the changes from IGF1 SDS at start of high-dose GH were also tested by means of linear regression. The significance level was set at 0.05.

\section{Results}

A complete analysis was carried out for the remaining 28 of 40 originally included patients $(70 \%)$. One female (BA 13) and one male (BA 15.5) from the control group had not reached AH, and their PAH (17) was used for further analysis. Patient characteristics at start, at stop, and at follow-up are listed in Table 1. Age and BMI SDS at baseline were higher in the GH-treated subjects compared with the controls (in the original cohort 
Table 1 Summary of initial and outcome variables mean (S.D). Results are presented as mean (S.D).

\begin{tabular}{|c|c|c|c|}
\hline & $\mathbf{G H}(n=16)$ & $\begin{array}{l}\text { Control } \\
(n=12)\end{array}$ & $\begin{array}{l}\text { Treatment } \\
\text { versus } \\
\text { control }(P)\end{array}$ \\
\hline Boys/girls & $12 / 4$ & $8 / 4$ & \\
\hline \multicolumn{4}{|l|}{ Start treatment } \\
\hline Age (years) ${ }^{\mathrm{a}}$ & $8.7(1.4)$ & $7.0(1.7)$ & 0.009 \\
\hline Bone age delay (years) & $3.0(1.1)$ & $2.2(1.3)$ & 0.07 \\
\hline$H(\mathrm{~cm})$ & $118.4(8.5)$ & $111.5(10.6)$ & 0.06 \\
\hline HSDS & $-2.9(0.6)$ & $-2.5(0.3)$ & 0.09 \\
\hline$H$ for BA SDS & $0.4(1.2)$ & $0.7(2.2)$ & 0.7 \\
\hline cTH SDS & $-0.7(0.5)$ & $-0.8(0.6)$ & 0.8 \\
\hline BMI SDS & $-0.6(0.8)$ & $-1.1(0.4)$ & 0.04 \\
\hline SH SDS & $-1.8(1.0)$ & $-1.9(0.5)$ & 0.1 \\
\hline Leg length SDS & $-2.9(0.7)$ & $-2.3(0.3)$ & 0.007 \\
\hline $\mathrm{SH} / H \mathrm{SDS}$ & $1.7(2.1)$ & $0.8(0.9)$ & 0.2 \\
\hline \multicolumn{4}{|c|}{ Discontinuation of treatment (stop) } \\
\hline Age (years) & $12.0(1.0)$ & $11.9(2.0)$ & 0.9 \\
\hline Age at T2 (years) & $11.6(1.2)$ & $12.1(2.0)$ & 0.5 \\
\hline Age at B2 (girls) & $10.7(1.2)$ & $11.5(1.3)$ & 0.5 \\
\hline Age at G2 (boys) ${ }^{c}$ & $12.0(1.0)$ & $12.3(2.2)$ & 0.7 \\
\hline T2 SDS & $0.3(0.7)$ & $-0.2(1.2)$ & 0.2 \\
\hline$H(\mathrm{~cm})$ & $144.5(5.6)$ & $135.8(6.4)$ & 0.001 \\
\hline HSDS & $-1.3(0.8)$ & $-2.6(0.8)$ & 0.001 \\
\hline$H$ for BA SDS & $-0.5(0.6)$ & $0.7(1.3)$ & 0.7 \\
\hline$H$ for BA SDS (stop-start) & $-1.2(0.8)$ & $-1.3(1.5)$ & 0.04 \\
\hline Bone maturation ${ }^{\text {d }}$ & $1.6(0.4)$ & $1.0(0.2)$ & 0.000 \\
\hline PAH SDS & $-1.3(0.9)$ & $-1.7(1.1)$ & 0.2 \\
\hline BMI SDS & $-0.2(1.0)$ & $-1.4(0.7)$ & 0.003 \\
\hline SH SDS & $-0.6(1.0)$ & $-1.7(0.6)$ & 0.02 \\
\hline Leg length SDS & $-1.8(0.8)$ & $-2.2(0.6)$ & 0.3 \\
\hline SH/HSDS & $1.4(1.0)$ & $1.1(1.4)$ & 0.6 \\
\hline Years from start to stop ${ }^{e}$ & $3.3(0.9)$ & $4.9(1.9)$ & 0.02 \\
\hline \multicolumn{4}{|l|}{ At adult height } \\
\hline Age (years) & $21.0(2.1)$ & $19.6(2.4)$ & 0.1 \\
\hline $\mathrm{AH}$ in males $(\mathrm{cm})$ & $169.7(4.2)$ & $168.8(3.8)$ & 0.6 \\
\hline $\mathrm{AH}$ in females $(\mathrm{cm})$ & $154.6(5.0)$ & $160.8(4.5)$ & 0.1 \\
\hline AH SDS & $-2.1(0.7)$ & $-1.9(0.6)$ & 0.6 \\
\hline $\mathrm{AH}-H_{\text {start }} \mathrm{SDS}$ & $0.7(0.6)$ & $0.7(0.6)$ & 0.8 \\
\hline $\mathrm{AH}-H$ for $\mathrm{BA}_{\text {start }}$ SDS & $-1.6(1.0)$ & $-1.3(1.1)$ & 0.5 \\
\hline $\mathrm{AH}-\mathrm{cTH}$ SDS & $-1.4(0.8)$ & $-1.1(0.4)$ & 0.4 \\
\hline $\mathrm{AH}-\mathrm{PAH}_{\text {stop }} \mathrm{SDS}$ & $-0.8(0.9)$ & $-0.1(1.3)$ & 0.1 \\
\hline BMI SDS & $0.6(1.0)$ & $-1.0(1.2)$ & 0.001 \\
\hline PBI SDS & $0.5(0.9)$ & $0.2(0.7)$ & 0.4 \\
\hline SH SDS & $-1.2(1.2)$ & $-1.7(1.0)$ & 0.2 \\
\hline Leg length SDS & $-2.1(0.6)$ & $-1.4(1.1)$ & 0.05 \\
\hline $\mathrm{SH} / H \mathrm{SDS}$ & $1.5(0.9)$ & $0.4(1.7)$ & 0.04 \\
\hline Untreated interval (years) & $9.0(1.5)$ & $7.8(2.1)$ & 0.07 \\
\hline
\end{tabular}

$\mathrm{AH}$, (adult) height; $\mathrm{BA}$, bone age; $\mathrm{PBI}$, pediatric bone index; $\mathrm{BMI}$, body mass index; CTH, conditional target height; LL, leg length; $\mathrm{PAH}$, predicted adult height; $\mathrm{SH}$, sitting height; $\mathrm{SH} / H$, sitting height/height ratio; T2, Tanner stage 2; $\mathrm{TH}$, target height.

${ }^{\text {a }}$ Start signifies the start of the on-off scheme.

bStop is defined as the moment of discontinuation of GH treatment in the $\mathrm{GH}$ -treated group and the moment of attainment of T2 in the control group.

${ }^{\mathrm{c}}$ Two boys from the control group had late pubertal onset at the age of 14.2 and 16.0 years respectively.

${ }^{\mathrm{d}}$ Bone maturation calculated for the full trial period.

e Includes the first year's on-off scheme.

of 40 patients, this was not significant). GH-treated children tended to have more BA delay than controls. The mean GH treatment period was 3.3 years (including the first year's on-off scheme), resulting in a mean high-dose GH treatment duration of 2.3 years (range 2.0-5.0 years, with the exception of one boy who stopped after 1.2 years). Children in the control group were seen for a period of 4.9 (1.9) years. AH data were collected at a mean age of $20.4(2.3)$ years. The mean period that elapsed between treatment discontinuation and $\mathrm{AH}$ analysis was 8.5 (1.7) years (range 3.2-11.7 years).

\section{Effect on growth, bone maturation, and puberty}

At discontinuation of treatment, height SDS increased significantly in GH-treated children compared with the controls (Table 1, Fig. 3) as reported previously (8). Bone maturation in the first 2 years of treatment was faster in GH-treated children compared with the controls, both in the original cohort (3.6/2 vs $2.0 / 2$ years) and in the cohort available for $\mathrm{AH}$ evaluation (3.1/2 vs 2.1/2 years). Over the full trial period, bone maturation was also significantly advanced in GH-treated subjects compared with the controls (1.6 (0.4) years/years versus $1.0(0.2)$ years/years respectively, $P<0.001)$. PBI SDS was not different between the GH-treated and control groups (Table 1). Madelung's deformities or other apparent anatomical anomalies were not detected on the hand X-rays.

AH SDS, $\mathrm{AH}-\mathrm{H}_{\text {start }}$ SDS, $\mathrm{AH}-H$ for $\mathrm{BA}_{\text {start }}$ SDS, and AH - cTH SDS were not significantly different between the GH-treated and control groups (Table 1), and in both groups, $50 \%$ of the participants attained an $\mathrm{AH}$ $>-2.0$ SDS. The percentage of individuals with a height below the target range (cTH SDS - 1.6) decreased from 75 at start to $44 \%$ at follow-up in the GH-treated group and from 67 to $27 \%$ in the controls. The loss of growth potential after discontinuation of therapy $\left(\mathrm{AH}-\mathrm{PAH}_{\text {stop }}\right.$ SDS $)$ tended to be greater in the treated group compared with the controls, but the difference did not reach statistical significance $(P=0.1)$.

BMI was significantly higher in the GH group compared with the control group at all stages of the trial. At follow-up, BMI in GH-treated subjects was 1.0 S.D. higher than $\mathrm{BMI}_{\text {start }}$, while there was only an increment of 0.1 s.D. in the controls $(P<0.05)$.

At baseline, treatment and control groups were found to be slightly disproportionate, with relatively short legs in comparison to $\mathrm{SH}$, resulting in a positive SH/H SDS in both groups. At the end of the trial phase, SH/H SDS was similar, but at follow-up, it was significantly higher in the GH-treated group compared with the controls $(P=0.04)$. Figure 4 shows SH SDS, LL SDS, and SH/H SDS at start and at follow-up. GH-treated patients displayed an increased growth of trunk and legs compared with the controls during the 4 years after the start of the trial phase, whereas controls had more or less stable SH SDS and LL SDS, which increased after (more than) 4 years. The GH-treated group had a longer trunk, but shorter legs than controls at follow-up. 

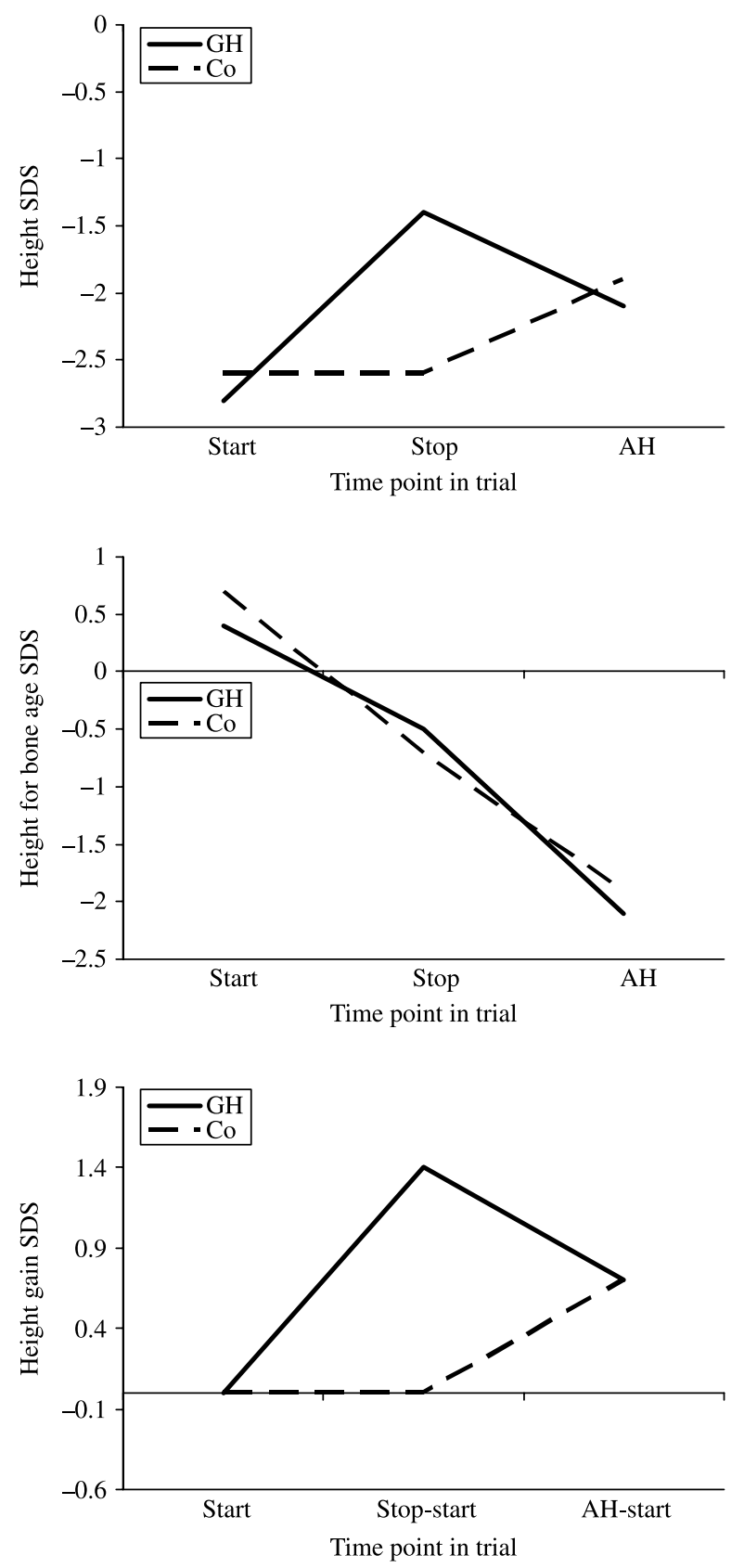

Figure 3 Height SDS, height for bone age SDS, and height gain SDS at start and discontinuation of the intervention, and after reaching adult height $(\mathrm{AH})$.

Our analysis 5 years after inclusion demonstrated significantly earlier pubertal onset in GH-treated subjects (8). However, in our present analysis on 26 of 28 subjects (missing data on pubertal onset for one patient from each group), the difference did not reach statistical significance $(P=0.5$; Table 1$)$. In boys in the treatment and control groups, pubertal onset ranged from 10.3 to 13.6 years and from 9.2 to 16.0 years respectively. In girls, these ranges were 9.2-12.1 years and 10.0-12.4 years respectively. At the attainment of Tanner stage 2, mean pubertal stage SDS for age (in boys and girls) was $0.3(0.7)$ and $-0.2(1.2)$ in the treatment and control groups respectively $(P=0.2)$. None of the 12 GH-treated subjects and two boys of eight controls had delayed puberty (at 14.2 and 16.0 years), while in both groups $50 \%$ of the patients had at least one parent (most often the father) with a reported late onset of puberty.

\section{Linear regression analysis of predictors for growth response}

Possible interactions between the effect of GH treatment on the four $\mathrm{AH}$ outcome parameters and on $\mathrm{AH}-\mathrm{PAH}_{\text {stop }}$ and the baseline parameters gender, age $_{\text {start }}, H_{\text {start }}$, and BA delay were analyzed. Age at baseline was a predictor for the treatment effect $(\mathrm{GH}$ $\times$ age $\left._{\text {start }}\right)$ expressed as $\mathrm{AH}(B=0.4,95 \% \mathrm{CI}=0.03-0.7$, $P=0.04)$ and $\mathrm{AH}-H_{\text {start }}(B=0.4,95 \% \mathrm{CI}=0.06-0.7$, $P=0.02)$, but not for the other outcome parameters, thus older children had a better response to treatment. Gender showed a negative interaction with treatment effect $(\mathrm{GH} \times$ gender $)$ for $\mathrm{AH}(B=-1.1$, $\mathrm{CI}=-2.3-0.01, P=0.052$ ), with boys showing a larger
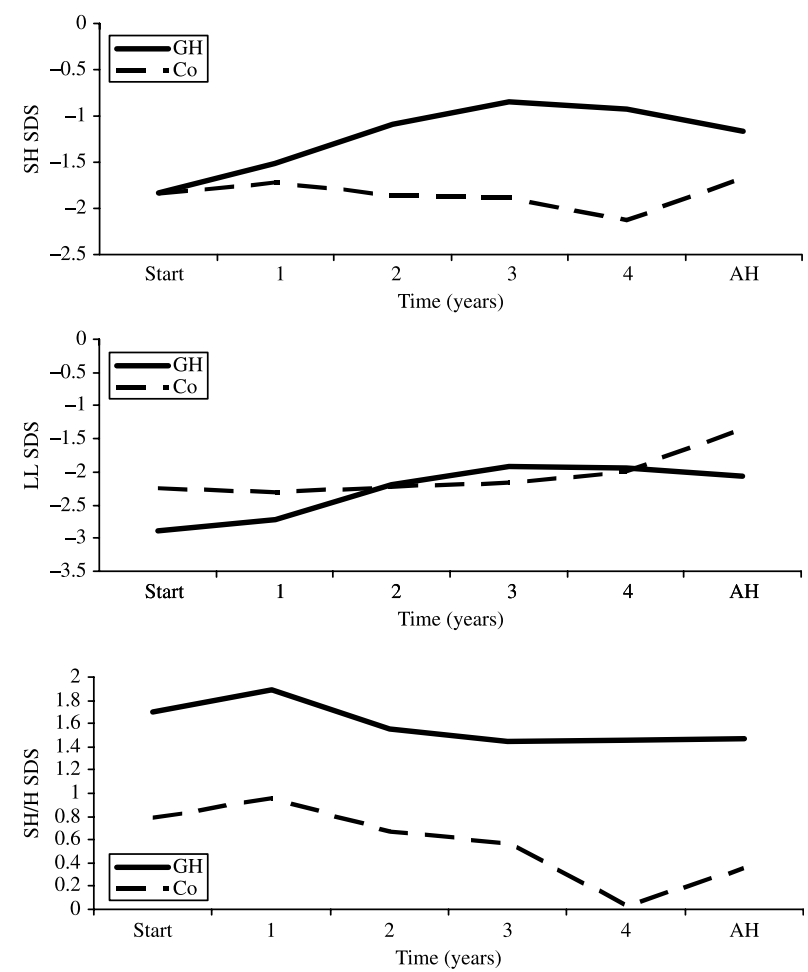

Figure 4 Development of SH SDS, LL SDS, and SH/H SDS during 4 years after onset of the trial phase and during follow-up until $\mathrm{AH}$. At start and on $\mathrm{AH}$, data of $100 \%$ of the patients are represented. After $1,2,3$, or 4 years from start of the trial phase, data of 96,89 , 89 , and $61 \%$ of the patients are shown. 
increase in AH SDS than girls. Height and BA delay at start were not significant predictors for treatment effect in any of the outcome parameters.

IGF1 SDS after 3 months of treatment with $2.0 \mathrm{mg} / \mathrm{m}^{2} \mathrm{GH}$ was associated with growth potential loss, with higher IGF1 levels resulting in a higher loss of growth potential expressed as $\mathrm{AH}-\mathrm{PAH}_{\text {start }}(B=-0.6$, $95 \% \mathrm{CI}=-1.2-(-0.02), P=0.045)$. The change in IGF1 SDS between start and 3 months of high-dose GH treatment showed a trend toward negative interactions with treatment effect being expressed as AH SDS $(B=-0.5,95 \% \quad C I=-1.0-(-0.1), \quad P=0.09)$ and $\mathrm{AH}-H$ for $\mathrm{BA}_{\text {start }}$ SDS $(B=-1.0$, 95\% CI $=-2.0-$ $(-0.1), P=0.07)$, with higher changes in IGF1 SDS over 3 months of high-dose $\mathrm{GH}$ treatment showing lower increases in $\mathrm{AH}$ SDS and $\mathrm{AH}-H$ for $\mathrm{BA}_{\text {start }}$ SDS.

\section{Genetic analysis}

Informed consent for genetic analysis was obtained from 18 of 28 patients (11 GH-treated subjects and 8 controls). SNP array did not detect insertions, deletions, or duplications explaining short stature. Mutational analysis was not performed.

\section{Discussion}

The long-term results of this first randomized controlled study on the effect of high-dose GH treatment restricted to the prepubertal period show that this regimen does not lead to an increased AH. This confirms our earlier findings after discontinuation of treatment, where we showed that the positive growth response significantly accelerated skeletal maturation and advanced the onset of pubertal development, and did not improve PAH (8). In contrast to retrospective studies (3), where the growth response was inversely associated with age at start of the treatment, in our study a younger age at start was associated with a lower $\mathrm{AH}$.

The lack of effect of this therapeutic regimen can be explained in at least three ways. The most likely explanation is that a high GH dose (approximately three times higher than substitution) (23) administered to young children not only leads to faster growth but also results in faster bone maturation. There are few data on GH treatment of young children with ISS, as in virtually all studies, the average age was $\sim 11$ years. It seems unlikely that the high-dose per se causes the lack of effect, because children treated with a high GH dosage ( $67 \mu \mathrm{g} / \mathrm{kg}$ per day) starting at a mean age of 11 years achieve an AH gain of 1.3 s.D., which is slightly more than that achieved on $33 \mu \mathrm{g} / \mathrm{kg}$ per day (24). We speculate that the epiphyseal plates of young children may be more sensitive to high doses of GH and/or IGF1 than at later ages. The finding that a higher IGF1 SDS after 3 months of high-dose GH treatment was associated with less $\mathrm{AH}$ gain would suggest that circulating IGF1 plays a role in advancing epiphyseal maturation. The report by Cohen et al. (2007) that even on a high $\mathrm{GH}$ dose (median 98, range 20-346 $\mu \mathrm{g} / \mathrm{kg}$ per day) titrated on circulating IGF1 levels of +2 SDS, administered to young children (age range 2.9-13.5 years, mean 7.53), no BA advance observed is not necessarily in contradiction with our findings, as the dose range in that study was large, and the children who needed high $\mathrm{GH}$ doses to reach the aimed IGF1 level may have been more resistant to GH. The trend toward a worse response to treatment in females may reflect the relatively strong influence of estrogens on bone maturation.

The second explanation is that the effect on bone maturation may be caused by the on-off GH treatment scheme employed during the first year of the trial, which may have primed the epiphyseal growth plate. We cannot exclude this possibility, but should consider it less likely than the first explanation. The third explanation, which also cannot be ruled out with certainty, is that the poor result may be due to discontinuation of GH in puberty. The discontinuation of GH may have led to a 'catch-down' phenomenon, as was shown previously in children with short for gestational age, who showed attenuation of growth after discontinuation of GH while puberty (and thus skeletal maturation) was progressing (25). However, the equal PAH in the $\mathrm{GH}$-treated and control groups at discontinuation of the trial phase argues against this hypothesis.

There are two noteworthy limitations of our study. First, the long diagnostic phase that may have been a confounder of the effect of long-term GH therapy. Secondly, the small size of the cohort. With respect to the latter limitation, we believe that even in this small study group, the absence of any effect of treatment makes it very unlikely that this is a false negative result.

Our results imply that there may be an inverse $U$-shaped relationship between $\mathrm{GH}$ dose and $\mathrm{AH}$ gain, if treatment is started at a young age. Dose is positively associated with $\mathrm{AH}$ gain in the range of $25-50 \mu \mathrm{g} / \mathrm{kg}$ per day (2), but in young children higher doses may decrease $\mathrm{AH}$ gain due to accelerated maturation of the epiphyseal plates and possibly also of the GnRH regulatory center, while the effect on growth has reached a plateau. This observation appears in contradiction to the overgrowth and tall $\mathrm{AH}$ of children with pituitary gigantism, but in that condition, plasma GH levels are characterized by an elevated baseline without high peaks, while the GH profile on a high GH dose shows one very high peak per day, followed by $\sim 12$ h of suppression. During the peak, plasma free GH must be considerably higher than that in children with pituitary gigantism. Furthermore, the different GH profiles may also have different biological effects, similarly to observations in rodents (26). 
The effect of a high GH dosage on pubertal onset in young children is less clear. In the final analysis on 26 children using a novel technique for expressing pubertal stage in SDS (correcting for age and gender) (18), we found a trend $(P=0.2)$, but no statistically significant difference between the groups at Tanner stage 2. While this technique enables appropriate correction for the (statistically significant) age difference at the start of the trial between the groups, the inability to reach statistical significance may well be related to the limited number of subjects who could be studied at follow-up. In the larger group of 35 subjects studied 5 years after inclusion, the age difference at start did not reach significance, some patients had not yet entered puberty at the moment of analysis, and another method (cumulative proportions of patients having entered puberty, and calculation of relative risk) was used. In that analysis, the relative risk for early puberty, adjusted for age and sex, was 4.7 (1.4$15.8, P=0.012$ ) (8). There are two other observations that can serve as indirect evidence for an effect on puberty onset. First, the observation that none of the 12 males in the GH treatment group entered puberty late compared with two of the eight controls. Secondly, at follow-up, the GH-treated subjects had a significantly shorter LL than controls and a higher SH/H SDS, suggesting earlier exposure to sex steroids. The higher $\mathrm{SH} / \mathrm{H}$ ratio may also explain the increase in BMI SDS observed in the GH-treated children (27). Unfortunately, the study design during follow-up did not allow for the collection of sufficient data on the progression of puberty.

The untreated controls not only serve as comparison for the GH-treated children, but also illustrate the natural history of ISS. Up to early adolescence, height SDS remained stable at -2.6 , but $\mathrm{AH}$ was 0.7 S.D. higher than height SDS at start, presumably due to a rather delayed and possibly protracted puberty. A similar pattern was seen for SH and LL SDS. This result confirms our and others' earlier findings $(28,29)$. It also shows that HSDS for BA in young children severely over-predicts AH. However, the average PAH according to Bayley and Pinneau at discontinuation of the trial was almost identical to the attained $\mathrm{AH}$, consistent with our previous report (30).

In conclusion, high-dose GH treatment limited to the prepubertal period in young children with ISS has no effect on AH, probably caused by concomitant advance of bone maturation, and may advance pubertal onset.

\section{Declaration of interest}

The authors declare that there is no conflict of interest that could be perceived as prejudicing the impartiality of the research reported.

\section{Funding}

This work was supported by a grant from ZonMW, The Netherlands Organisation for Health Research and Development (grant number 920-03-392, to S A van Gool); and by Pfizer (New York, NY, USA).

\section{Author contribution statement}

We greatly appreciate the contributions of $\mathrm{H}$ Visser-van Balen and $\mathrm{J}$ Looij in performing measurements, and the financial support of Pfizer (New York, NY, USA) for this study.

\section{Acknowledgements}

We express our gratitude to Hans van der Horst, Annelies van Gool, Simone Sanders, and Anna Rompen from Justus Medical Center (Eindhoven, The Netherlands) for facilitating our study. The authors are grateful to Pfizer (New York, NY, USA) for supply of recombinant hGH.

\section{References}

1 Wit JM, Reiter EO, Ross JL, Saenger PH, Savage MO, Rogol AD \& Cohen P. Idiopathic short stature: management and growth hormone treatment. Growth Hormone \& IGF Research $2008 \mathbf{1 8}$ 111-135.

2 Cohen P, Rogol AD, Deal CL, Saenger P, Reiter EO, Ross JL, Chernausek SD, Savage MO \& Wit JM on behalf of the 2007 ISS Consensus Workshop Participants. Consensus statement on the diagnosis and treatment of children with idiopathic short stature: a summary of the Growth Hormone Research Society, the Lawson Wilkins Pediatric Endocrine Society, and the European Society for Paediatric Endocrinology Workshop. Journal of Clinical Endocrinology and Metabolism 200893 4210-4217.

3 Ranke MB, Lindberg A, Price DA, Darendeliler F, AlbertssonWikland K, Wilton P \& Reiter EO on behalf of the KIGS International Board. Age at growth hormone therapy start and first-year responsiveness to growth hormone are major determinants of height outcome in idiopathic short stature. Hormone Research $20076853-62$.

4 Lesage C, Walker J, Landier F, Chatelain P, Chaussain JL \& Bougneres PF. Near normalization of adolescent height with growth hormone therapy in very short children without growth hormone deficiency. Journal of Pediatrics 1991119 29-34.

5 Bourguignon JP, Vandeweghe M, Vanderschueren-Lodeweyckx M, Malvaux P, Wolter R, Du Caju M \& Ernould C. Pubertal growth and final height in hypopituitary boys: a minor role of bone age at onset of puberty. Journal of Clinical Endocrinology and Metabolism $198663376-382$.

6 Rikken B, Massa GG \& Wit JM. Final height in a large cohort of Dutch patients with growth hormone deficiency treated with growth hormone. Dutch Growth Hormone Working Group. Hormone Research 199543 135-137.

7 Rekers-Mombarg LT, Kamp GA, Massa GG \& Wit JM. Influence of growth hormone treatment on pubertal timing and pubertal growth in children with idiopathic short stature. Dutch Growth Hormone Working Group. Journal of Pediatric Endocrinology and Metabolism $199912611-622$.

8 Kamp GA, Waelkens JJ, de Muinck Keizer-Schrama SMPF, Delemarre-Van de Waal HA, Verhoeven-Wind L, Zwinderman AH \& Wit JM. High dose growth hormone treatment induces acceleration of skeletal maturation and an earlier onset of puberty in children with idiopathic short stature. Archives of Disease in Childhood 200287 215-220.

9 Kamp GA, Zwinderman AH, Van Doorn J, Hackeng W, Frölich M, Schönau E \& Wit JM. Biochemical markers of growth hormone (GH) sensitivity in children with idiopathic short stature: individual capacity of IGF-I generation after high-dose GH treatment determines the growth response to GH. Clinical Endocrinology 200257 315-325.

10 Kamp GA, Ouwens DM, Hoogerbrugge CM, Zwinderman AH, Maassen JA \& Wit JM. Skin fibroblasts of children with idiopathic short stature show an increased mitogenic response to IGF-I and secrete more IGFBP-3. Clinical Endocrinology 200256 439-447. 
11 Roede MJ \& van Wieringen JC. Growth diagrams 1980. Netherlands third nationwide survey. Tijdschrift voor Sociale Gezondheidszorg 198563 1-34.

12 Usher R \& McLean F. Intrauterine growth of live-born Caucasian infants at sea level: standards obtained from measurements in 7 dimensions of infants born between 25 and 44 weeks of gestation. Journal of Pediatrics 1969 74 901-910.

13 Gerver WMJ \& De Bruin R. Paediatric Morphometrics: A Reference Manual. Utrecht, The Netherlands: Bunge, 1996.

14 Fredriks AM, van Buuren S, Jeurissen SE, Dekker FW, Verloove-Vanhorick SP \& Wit JM. Height, weight, body mass index and pubertal development reference values for children of Turkish origin in The Netherlands. European Journal of Pediatrics 2003162 788-793.

15 Greulich WW \& Pyle SI. Radiographic Atlas of Skeletal Development of Hand and Wrist, 2nd edn. Stanford: Stanford University Press, 1959.

16 Gijsbers AC, Lew JY, Bosch CA, Schuurs-Hoeijmakers JH, van Haeringen A, den Hollander NS, Kant SG, Bijlsma EK, Breuning MH, Bakker E \& Ruivenkamp CA. A new diagnostic workflow for patients with mental retardation and/or multiple congenital abnormalities: test arrays first. European Journal of Human Genetics 200917 1394-1402.

17 Bayley N \& Pinneau SR. Tables for predicting adult height from skeletal age: revised for use with the Greulich-Pyle hand standards. Journal of Pediatrics $1952 \mathbf{4 0} 423-441$.

18 van Buuren S \& Ooms JC. Stage line diagram: an age-conditional reference diagram for tracking development. Statistics in Medicine 200928 1569-1579.

19 Fredriks AM, van Buuren S, Burgmeijer RJ, Meulmeester JF, Beuker RJ, Brugman E, Roede MJ, Verloove-Vanhorick SP \& Wit JM. Continuing positive secular growth change in The Netherlands 1955-1997. Pediatric Research 2000 47 316-323.

20 Thodberg HH, van Rijn RR, Tanaka T, Martin DD \& Kreiborg S. A paediatric bone index derived by automated radiogrammetry. Osteoporosis International 2009 In press. DOI: 10.1007/s00198009-1085-9.

21 Hermanussen $\mathrm{M}$ \& Cole J. The calculation of target height reconsidered. Hormone Research 200359 180-183.

22 Fredriks AM, van Buuren S, van Heel WJ, Dijkman-Neerincx RH, Verloove-Vanhorick SP \& Wit JM. Nationwide age references for sitting height, leg length, and sitting height/height ratio, and their diagnostic value for disproportionate growth disorders. Archives of Disease in Childhood 200590 807-812.

23 Jorgensen JO, Flyvbjerg A \& Christiansen JS. The metabolic clearance rate, serum half-time and apparent distribution space of authentic biosynthetic human growth hormone in growth hormone-deficient patients. Acta Endocrinologica 1989120 8-13.

24 Albertsson-Wikland K, Aronson AS, Gustafsson J, Hagenäs L, Ivarsson SA, Jonsson B, Kriström B, Marcus C, Nilsson KO, Ritzén EM, Tuvemo T, Westphal O \& Aman J. Dose-dependent effect of growth hormone on final height in children with short stature without growth hormone deficiency. Journal of Clinical Endocrinology and Metabolism 200893 4342-4350.

25 Fjellestad-Paulsen A, Simon D \& Czernichow P. Short children born small for gestational age and treated with growth hormone for three years have an important catch-down five years after discontinuation of treatment. Journal of Clinical Endocrinology and Metabolism 200489 1234-1239.

26 Gevers EF, Wit JM \& Robinson IC. Growth, growth hormone (GH)-binding protein, and GH receptors are differentially regulated by peak and trough components of the $\mathrm{GH}$ secretory pattern in the rat. Endocrinology $19961371013-1018$.

27 Van den BJ \& Wit JM. Anthropometry and body composition in children. Hormone Research 199748 33-42.

28 Wit JM, Clayton PE, Rogol AD, Savage MO, Saenger PH \& Cohen P. Idiopathic short stature: definition, epidemiology, and diagnostic evaluation. Growth Hormone \& IGF Research 2008 18 89-110.

29 Rekers-Mombarg LT, Wit JM, Massa GG, Ranke MB, Buckler JM, Butenandt O, Chaussain JL, Frisch H \& Leiberman E. Spontaneous growth in idiopathic short stature. Archives of Disease in Childhood 199675 175-180.

30 Wit JM \& Rekers-Mombarg LT. Final height gain by GH therapy in children with idiopathic short stature is dose dependent. Journal of Clinical Endocrinology and Metabolism 200287 604-611.

Received 5 January 2010

Accepted 28 January 2010 